BERKALA FISIKA INDONESIA

\title{
Resonansi Helmholtz: Pegas dalam botol
}

\section{Fitri Kurnia Dewi ${ }^{1 *}$, Okimustava ${ }^{2}$}

1,2 Pendidikan Fisika, Fakultas Keguruan dan Ilmu Pendidikan, Universitas Ahmad Dahlan, Indonesia Email: fitrikurnia354@gmail.com*

* Penulis korespondensi

\begin{tabular}{l}
\hline Informasi artikel \\
\hline Sejarah artikel: \\
Dikirim \\
Revisi \\
Diterima \\
\hline
\end{tabular}

\section{Kata kunci:}

Frekuensi akustik

Frekuensi helmholtz

Resonansi helmholtz

\begin{abstract}
ABSTRAK
Penelitian ini bertujuan untuk menemukan nilai frekuensi akustik dari botol. Resonansi Helmholtz yang digunakan dalam penelitian ini adalah frekuensi Helmholtz pada botol kaca bekas sirup. Penelitian ini dilakukan dengan memanfaatkan sebuah botol yang memiliki leher untuk mengetahui nilai resonansi Helmholtz. Pengukuran resonansi Helmholtz menggunakan aplikasi dari android yaitu spectroid karena dapat mengukur besar frekuensi dan $\mathrm{dB}$. Hasil yang diperoleh yaitu terjadi penurunan frekuensi pada variasi volume ke $2.1224955 \mathrm{~m}^{3}$. Berdasarkan data yang diperoleh sesuai dengan prinsip Helmholtz. Semakin besar volume udara maka akan semakin kecil frekuensinya. Sedangkan nilai dB akan kecil jika volume makin kecil.
\end{abstract}

This is an open access article under the CC-BY-SA license

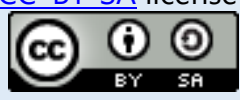

\section{Keywords:}

Acoustic frequency Helmholtz frequency

Helmholtz resonance

\begin{abstract}
Helmholtz Resonance: Spring in a Bottle. This study aims to find the acoustic frequency value of the bottle. The Helmholtz resonance used in this study was the Helmholz frequency in used glass bottles of syrup. This research was conducted by utilizing a bottle with a neck to determine the resonance value of the Helmholtz. Helmholtz resonance measurement uses an application from the android, namely the spectroid, to measure the frequency and dB. The results obtained are a decrease in frequency at the volume variation to $2,1224955 \mathrm{~m}^{3}$. Based on the data obtained following the Helmholtz principle. The greater the air volume, the smaller the frequency. Meanwhile, the $\mathrm{dB}$ value will be smaller than the volume.
\end{abstract}

How to Cite:

Dewi, F. K., \& Okimustava. (2020). Resonansi Helmholtz: Pegas dalam botol. Berkala Fisika Indonesia: Jurnal Ilmiah Fisika, Pembelajaran dan Aplikasinya, 11(2), 45-52. 


\section{Pendahuluan}

Dalam kehidupan sehari-hari, kita selalu berinteraksi dengan bunyi. Bunyi adalah gelombang mekanis yang merambat yang masih bisa ditangkap oleh telinga manusia, dengan rentang frekuensi 20 - $20 \mathrm{kHz}$. Sedangkan suara adalah bunyi manusia (Meyer et al., 1958). Bunyi memiliki banyak sifat salah satunya yaitu resonansi. Resonansi adalah fenomena yang ada dan sering kali ditemui di banyak sistem.

Resonator Helmholtz (HR) merupakan peristiwa resonansi yang terjadi pada dinding-kaku yang memiliki rongga dan memiliki ruang yang kecil kemudian di bagian tengah memiliki ruang yang lebih besar (Jena et al., 2019). Aplikasi HR telah digunakan untuk meredam kebisingan yang dihasilkan oleh elemen penginduksi di berbagai sistem struktural saluran, seperti ventilasi dan AC untuk gedung, sistem saluran otomatis dan mesin udara (Cai \& Mak, 2018). Awal mulanya resonator Helmholtz dimanfaatkan sebagai filter dari frekuensi akustik. Ketika suatu rongga ditiup maka akan muncul gema dengan frekuensi tertentu. Ketika satu hembusan melewati bagian atas botol kosong, resonansi Helmholtz terjadi, yang merupakan peristiwa resonansi udara dalam satu rongga (Abbad et al., 2019). Ketika udara mengisi rongga, tekanan di dalam naik, gaya luar yang menekan udara hilang, dan udara di dalam mulai keluar. Udara yang keluar akan menggantikan udara yang terjebak di leher botol. Dengan berkurangnya tekanan, mekanisme ini akan mereplikasi dirinya sendiri (Komkin et al., 2017). Ini adalah hasil yang sama seperti saat sebuah massa diikat oleh pegas. Udara rongga berfungsi sebagai pegas. Massa sama dengan resonator berisi udara. Pegas akan lebih lemah jika memiliki lubang yang lebih luas dengan jumlah udara yang lebih banyak, begitu pula sebaliknya. Karena udara di leher bertindak sebagai massa dan bergerak, ia memperoleh momentum (Han, 2008). Sehingga Pembentukan suatu massa leher yang teratur dapat menyebabkan terganggunya pergetaran (Chen \& Sun, 1991). Karena gangguan ini memberikan suatu aksi peredaman yang kuat pada gerakan gas, pengaturan yang lebih kuat dari resonator dilemahkan. Selain itu, pusaran tertentu dalam turbulensi dapat distabilkan oleh osilasi resonator dan kemudian memancarkan suara siulan ke dalam aliran saluran (Meyre,1958) Dengan menggunakan botol yang merupakan resonator dengan rongga terbuka. Yang mana ini memiliki keuntungan yang lebih dikarenakan karakteristik aliran resonator rongga terbuka lebih stabil dibandingkan resonator rongga tertutup (Stein \& Sesterhenn, 2019). Sehingga dengan demikian kita dapat menentukan kecepatan aliran optimal untuk menghasilkan sinyal yang baik dengan memperhatikan energi yang diperlukan dan meminimalisir ketidakstabilan pada kecepatan aliran (Njane et al., 2018).

Hal ini yang terjadi pada alat akustik yang terbuat dari botol dan menghasilkan suara siulan yang berbeda ketika ditiup. Meskipun menghasilkan siulan, ada beberapa hal yang dapat menghasilkan kebisingan baru dan merusak kapasitas redaman peredam resonator sampai batas tertentu sehingga untuk menghasilkan suara musik akustik yang bagus maka perlu diteliti bagaimana hubungan antara volume dan frekuensi untuk mendapatkan turbulensi ini yang dapat menjaga efektivitas resonator pada 
level tingginya (Zhao et al., 2017). Selain itu resonator Helmholtz juga sering dimanfaatkan sebagai salah satu metode yang digunakan dalam bidang peredaman bunyi (Kamila et al., 2016).

Beberapa penelitian telah dilakukan mengenai Resonansi Helmholtz. Penelitian yang dilakukan oleh Wang yaitu mengenai penghalang kebisingan permanen energi akustik terbaru dan terbarukan menggunakan resonator Helmholtz dan film Polyvinylidene Fluoride (PVDF) untuk mengubah energi akustik kebisingan frekuensi rendah dari kereta api berkecepatan tinggi menjadi listrik. Penelitian ini dilakukan pada tahun 2018 dengan hasil tegangan output maksimum seketika sebesar 74,6 mV pada $110 \mathrm{~dB}(\mathrm{SPL})$, memverifikasi efisiensi dan keterbacaan sistem penghalang kebisingan pemanenan energi akustik yang diusulkan diterapkan untuk energi terbarukan di kereta api berkecepatan tinggi (Wang et al., 2018). Penelitian lainnya dilakukan oleh Cai dan kolega pada tahun 2017 yaitu mengenai peningkatan kinerja pelemahan kebisingan dari sistem resonator Helmholtz (HR) yang terkonduksi dan sepenuhnya memanfaatkan ruang yang tersedia. Dengan menambahkan HR pada ruang yang tersedia ke arah melintang, sistem HR saluran yang dimodifikasi diusulkan. Perambatan gelombang dalam sistem HR berkala dan sistem HR yang dimodifikasi diselidiki secara teoritis dan numerik (Cai et al., 2017). Susanto merancang resonator Helmholtz sebagai filter frekuensi suara. Resonator Helmholtz (HR) digunakan secara seri dan paralel dengan analogi resistor selama percobaan (Susanto, 2014). Romadhona memperluas studinya dengan menggunakan resonator Helmholtz berpasangan untuk meningkatkan kemampuan penyerapan suara pada komponen hamburan suara kayu. Bentuk tabung elemen hamburan suara ini dibangun dari limbah kayu gelondongan dari industri furnitur. Resonator Helmholtz elemen hamburan suara dibuat pada komputer dengan tiga diameter elemen yang berbeda, masing-masing 4, 6, dan $8 \mathrm{~cm}$ (Romadhona, 2017). Sedangkan pada penelitian yang akan dilakukan yaitu menemukan nilai frekuensi yang baik untuk akustik dari botol. Penelitian ini diharapkan dapat menjadi referensi dari penerapan hukum Helmholtz yaitu untuk penyerapan bunyi bising.

\section{Metode}

Penelitian ini dilakukan dengan memanfaatkan sebuah botol yang memiliki leher untuk mengetahui nilai resonansi Helmholtznya. Pengukuran resonansi Helmholtz yaitu menggunakan aplikasi dari android yaitu spectroid yang mana di dalam aplikasi tersebut dapat diukur besar frekuensi dan $\mathrm{dB}$. Untuk botolnya sendiri dipasangi sebuah kawat yang dibentuk sedemikian rupa seperti yang ada di Gambar 1. Kawat ini berfungsi untuk meletakan smartphone saat proses pengukuran sehingga pengukuran frekuensi menggunakan smartphone tepat berada di atas lubang botol.

Dalam penelitian ini, frekuensinya diukur menggunakan variasi volume. Variasi volume dilakukan dengan cara mengisi botol dengan air sehingga volume udara di dalam botol semakin berkurang. Setelah didapatkan frekuensi melalui pengukuran menggunakan aplikasi kemudian akan dibandingkan dengan hasil perhitungan dengan menggunakan persamaan (1). 


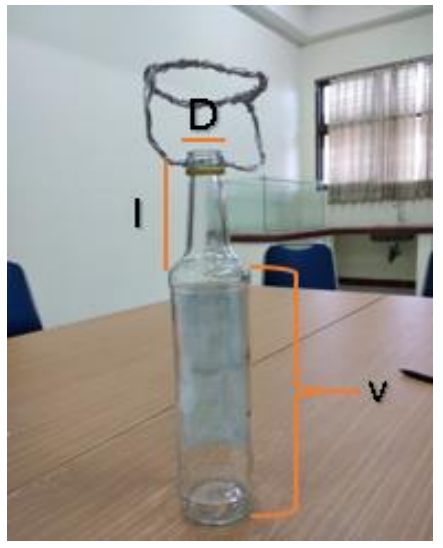

Gambar 1. Botol dengan ukuran $V=5,118959 \mathrm{~m}^{3}$

$$
f=\frac{V_{\text {sound }}}{2 \pi} \sqrt{\frac{A}{\ell \cdot V}}
$$

Dimana $A$ adalah luas permukaan dibagian leher, $V_{\text {sound }}$ adalah kecepatan bunyi dan $\ell_{\text {adalah }}$ panjang yang setara dengan leher,

Prosedur pengukuranya yaitu smartphone dipasang pada bagian atas botol, kemudian meniup bagian botol dalam kondisi kosong dan mengukur frekuensi yang dihasilkan dengan menggunakan aplikasi spectroid. Kemudian mencatat nilai frekuensi dan dB. Selanjutnya memvariasi ketinggian air dalam botol yaitu $2 \mathrm{~cm}$. Pengukuran dilakukan sebanyak delapan kali agar sesuai dengan tangga nada yang berjumlah delapan.

\section{Hasil dan Pembahasan}

Dari percobaan yang telah dilakukan diperoleh nilai frekuensi pada masing-masing volume sebagaimana yang ditampilkan dalam Gambar 1 sampai Gambar 8.

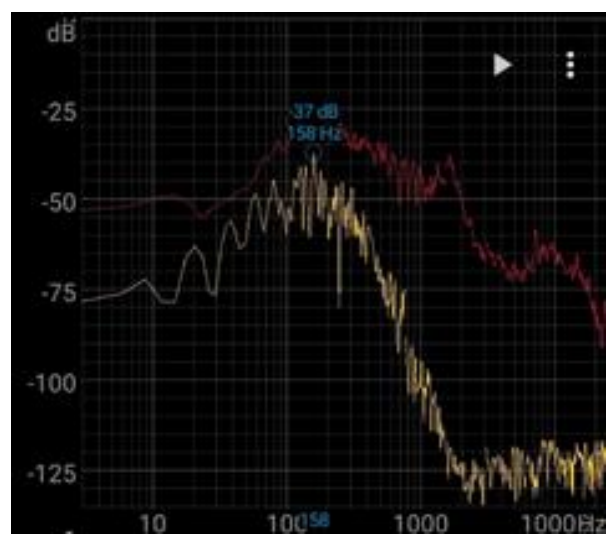

Gambar 1. Frekuensi ketika volume udara 5,11895988 $\mathrm{m}^{3}$ 


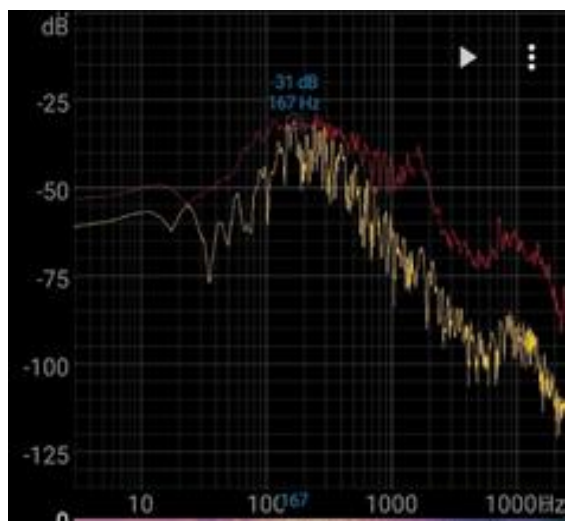

Gambar 2. Frekuensi ketika volume udara 4,61954916 m³

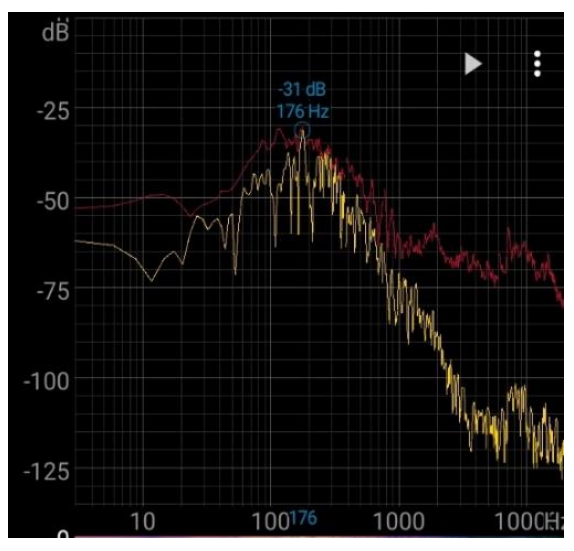

Gambar 3. Frekuensi ketikaVolume udara 4,12013844 m³

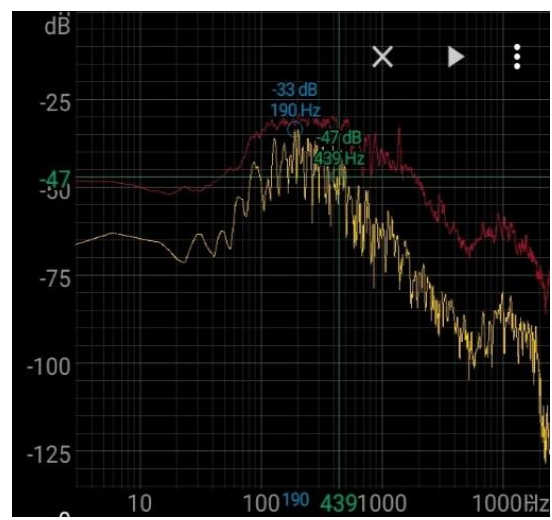

Gambar 4. Frekuensi ketika volume udara 3,62072772 m³

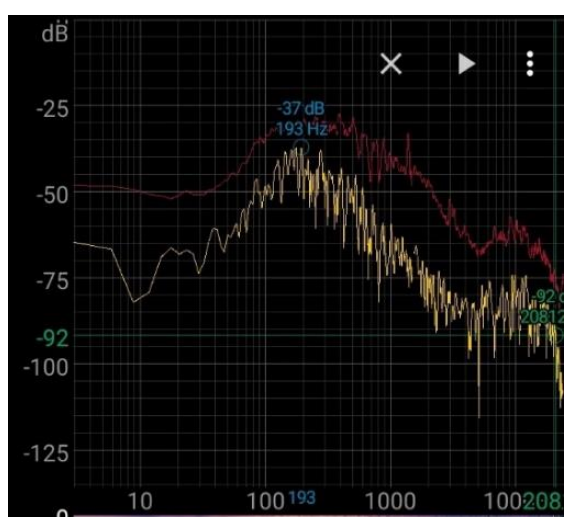

Gambar 5. Frekuensi ketika volume udara 3,121317 $\mathrm{m}^{3}$ 


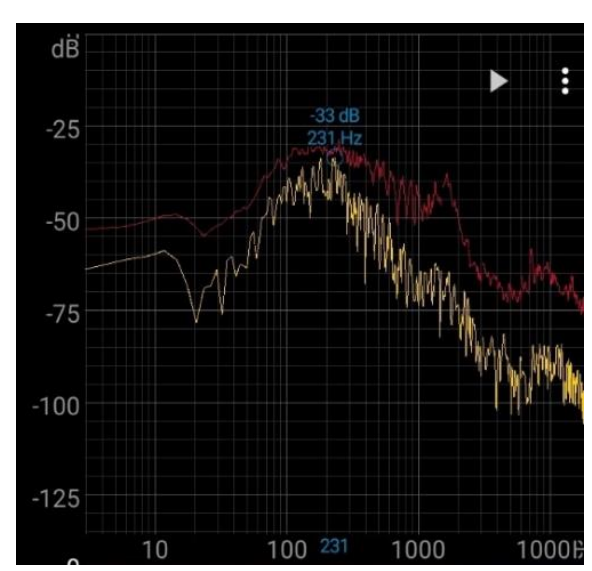

Gambar 6. Frekuensi ketika volume udara 2,62190628 $\mathrm{m}^{3}$

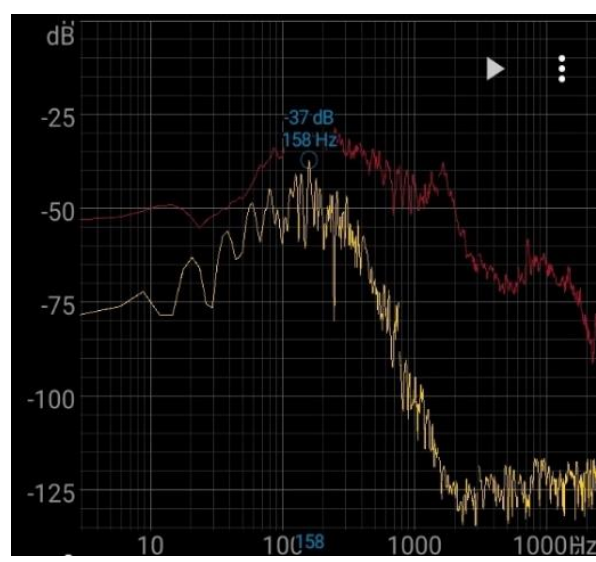

Gambar 7. Frekuensi ketika volume udara 2,12249556 $\mathrm{m}^{3}$

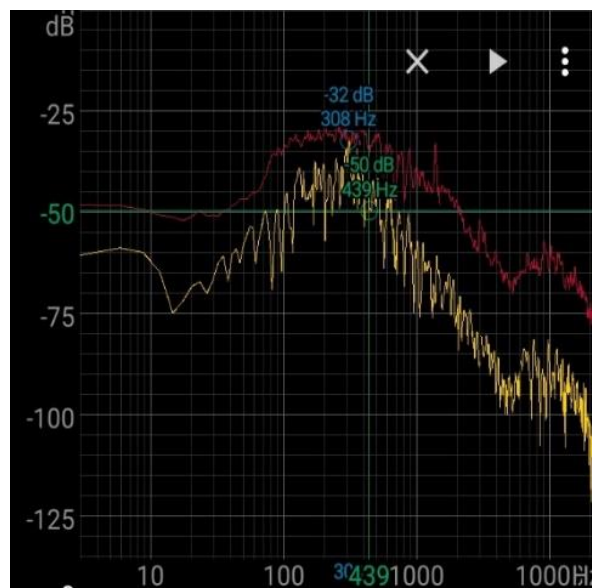

Gambar 8. Frekuensi ketika volume udara 2,16308484 m³

Dari data yang diperoleh di atas hasil pengukuran sangat berbeda dengan hasil perhitungan. Hal ini dimungkinkan berbedanya jenis botol yang digunakan oleh penulis makalah rujukan dengan penulis makalah ini. Selain itu juga terjadi penurunan frekuensi pada variasi volume ke 2,12249556 $\mathrm{m}^{3}$

Namun berdasarkan data yang diperoleh sesuai dengan prinsip helmholtz yang mana semakin kecil volume udara maka akan semakin kecil frekuensinya. Sedangkan nilai dB jika volume makin kecil maka dB juga semakin kecil. Hal ini dapat dilihat pada Gambar 9. 
Bebeda dengan hasil penelitian dari Cai et al. (2017). Hasil penelitian menunjukkan bahwa pita pelemahan kebisingan dan amplitudo puncak ditingkatkan dengan menambahkan HR. Sistem HR saluran yang diusulkan dapat meningkatkan kinerja pelemahan kebisingan dan sepenuhnya memanfaatkan ruang yang tersedia, dan praktis untuk digunakan dalam sistem saluran ventilasi actual.

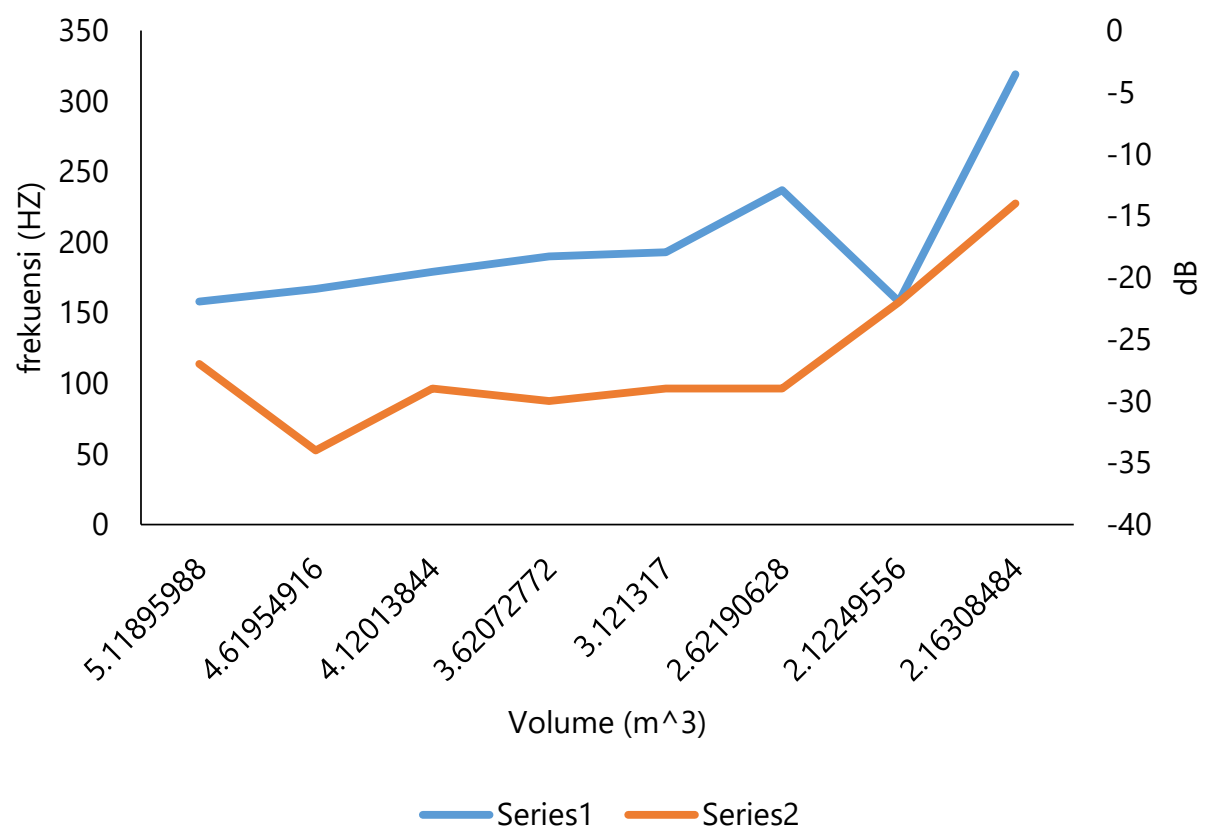

Gambar 9. Hubungan antara volume dan frekunsi dan dB

Kesimpulan ini tidak sama dengan kesimpulan Susanto. Mereka menggunakan program cool edit proV2,1 untuk membangun resonator Helmholtz dan mengukur tingkat suara. Temuan tersebut mengungkapkan bahwa resonator Helmholtz dengan satu HR, dua HR secara seri, dan dua HR secara paralel beroperasi pada frekuensi masing-masing $5,6 \mathrm{kHz}, 11,2 \mathrm{kHz}$, dan 2,8 kHz (Susanto, 2014). Namun temuan ini serupa dengan temuan Romadhona, yaitu penambahan resonator Helmholtz pada sampel berfungsi sesuai prediksi. Resonator Helmholtz digabungkan dengan kayu, kayu, frekuensi penyerapan suara. Semua sampel bekerja paling baik dalam rentang frekuensi 500-1000 Hz. Perpanjangan rongga leher dan resonator akan mentransfer keluaran sampel ke kayu, kayu, frekuensi penyerapan suara (Romadhona, 2017).

\section{Simpulan}

Kesimpulan dari penelitian ini yaitu semakin kecil volumenya maka nilai frekuensi semakin besar hal ini dikarenakan volume berbanding terbalik dengan nilai frekuensi. Selain itu, hal ini juga sesuai dengan prinsip dari pegas yang mana jika beban yang diberikan makin besar maka getarannya makin banyak dan frekuensinya semakin berat. Hal ini sesuai karena prinsip kerja resonansi Helmholtz digambarkan sebagai suatu massa yang dihubungkan dengan pegas. Udara yang ada di dalam botol 
sebagai pegasnya dan leher botol sebagai bebanya. Sehingga jika volume dalam botol berkurang maka pegasnya berkurang.

\section{References}

Abbad, A., Atalla, N., Ouisse, M., \& Doutres, O. (2019). Numerical and experimental investigations on the acoustic performances of membraned Helmholtz resonators embedded in a porous matrix. Journal of Sound and Vibration, 459, 114873.

Romadhona, I. C. (2017). Peningkatan kinerja serap bunyi pada elemen diffuser dengan penambahan resonator helmholtz tergandeng. Surakarta: Universitas Negeri Solo.

Cai, C., \& Mak, C. M. (2018). Acoustic performance of different Helmholtz resonator array configurations. Applied Acoustics, 130, 204-209.

Cai, C., Mak, C. M., \& Wang, X. (2017). Noise attenuation performance improvement by adding Helmholtz resonators on the periodic ducted Helmholtz resonator system. Applied Acoustics, 122, 8-15.

Chen, P., \& Sun, Z. (1991). A review of non-destructive methods for quality evaluation and sorting of agricultural products. Journal of Agricultural Engineering Research, 49, 85-98.

Han, M. (2008). Sound reduction by a Helmholtz resonator (Lehigh University). Retrieved from https://preserve.lib.lehigh.edu/islandora/object/preserve\%3Abp-3101590.

Jena, D. P., Dandsena, J., \& Jayakumari, V. G. (2019). Demonstration of effective acoustic properties of different configurations of Helmholtz resonators. Applied Acoustics, 155, 371-382.

Kamila, Z., Yahya, I., \& Utari, U. (2016). Influence of sugar palm ash fraction and resonator configuration on acoustic absorption performance of expose brick. Indonesian Journal of Applied Physics, 4(01), 19-27.

Komkin, A. I., Mironov, M. A., \& Bykov, A. I. (2017). Sound absorption by a Helmholtz resonator. Acoustical Physics, 63(4), 385-392.

Meyer, E., Mechel, F., \& Kurtze, G. (1958). Experiments on the influence of flow on sound attenuation in absorbing ducts. The Journal of the Acoustical Society of America, 30(3), 165-174.

Njane, S. N., Shinohara, Y., Kondo, N., Ogawa, Y., Suzuki, T., \& Nishizu, T. (2018). Improved underwater Helmholtz resonator with an open cavity for sample volume estimation. Computers and Electronics in Agriculture, 147, 18-26.

Stein, L., \& Sesterhenn, J. (2019). An acoustic model of a Helmholtz resonator under a grazing turbulent boundary layer. Acta Mechanica, 230(6), 2013-2029.

Susanto, R. (2014). Rancang bangun helmholtz resonator sebagai filter frekuensi dengan analogi resistor. In Seminar Nasional Pendidikan Sains IV 2014. Surakata: Universitas Sebelas Maret.

Wang, Y., Zhu, X., Zhang, T., Bano, S., Pan, H., Qi, L., ... Yuan, Y. (2018). A renewable low-frequency acoustic energy harvesting noise barrier for high-speed railways using a Helmholtz resonator and a PVDF film. Applied Energy, 230, 52-61.

Zhao, X., Cai, L., Yu, D., Lu, Z., \& Wen, J. (2017). A low frequency acoustic insulator by using the acoustic metasurface to a Helmholtz resonator. AIP Advances, 7(6), 065211. 